\title{
Medical Engineering Applications in Modern Medicine
}

\author{
Ethem Unal $^{1 *}$ and Mehmet Bozdoganoglu ${ }^{2}$ \\ ${ }^{1}$ Department of General Surgery, Turkey \\ ${ }^{2}$ Department of Mechanical Engineering, Turkey \\ *Corresponding author: Ethem Unal, , Umraniye Training and Resrarch Hospital, Department of General Surgery, Istanbul, Turkey
}

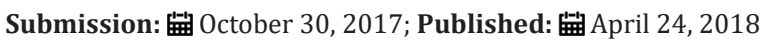

\section{Introduction}

Over the past years we have experienced a great technological development in health care and this is due to the joint work of engineers, mathematicians, physicians, computer scientists and many other professionals. Medical engineering (ME) is an exciting and emerging interdisciplinary field that combines engineering with life sciences.It can be summerized as the application of engineering principles to both the human body and to a broad range of instrumentation used in modern medicine. Recently, ME appliers gain the skills of engineering, whilst also providing employers with the added experience and knowledge of anatomy and physiology, and the ability to communicate with clinicians. Research of biomedical engineering has grown tremendously in the past few decades. Meanwhile, several outstanding journals in the field have emerged, with different emphases and objectives. These kind of journals constitutes a platform and a new forum for both scientists and clinicians to share their ideas and the results of their studies [1]. ME applications, basis and communications explores all facets of biomedical engineering, with emphasis on both the clinical and scientific aspects of the study. It covers the fields of bioelectronics, biomaterials, biomechanics, bioinformatics, nanobiological sciences and clinical engineering $[2,3]$.

Radiologic scanning instruments like computerized tomography and magnetic resonance imaging scans, haemodialysis machines, vacuum assisted closure (VAC) applications, all robotic and laparoscopic surgical devices and instruments, dentary implants and orthopedic devices, mechanically assisted respiratory machines used in anaesthesiology, cardiac pumps and electrical stimulators are just several examples for this issue.

All medical equipments need to be checked to ensure it is working correctly and safe for patients, and it is the role of healthcare science staff working in ME to do this.It is not just safety checks and maintenance, though. In ME, you would also get involved with the entire equipment lifecycle, including acceptance testing of new equipment, introducing equipment and devices into service, advising on the correct use of equipment, addressing patient safety issues, safely disposing of old devices etc. ME is a really exciting and varied role where you will use your expertise in electronic or mechanical engineering to undertake these activities and perhaps become involved in modifying or constructing equipment as well.

The practitioners undertake a hands-on role with medical devices, working with a wide range of equipment commonly encountered in the hospital environment. They might specialise in certain types of equipment such as that used in renal or radiotherapy treatment, for example. Clinical scientists should specialise in medical device risk management and governance where the role will be more focused on the effective management of equipment, for example ensuring equipment is replaced in a timely fashion and that risks associated with the use of equipment are minimised. Both roles complement each other and collectively contribute to patient health and well-being.

In conclusion, clinicians increasingly rely on the skills of healthcare science staff in ME and so you will regularly liaise with other scientists such as mechanical engineers, doctors and healthcare and/or engineering professionals as part of a multidisciplinary team, all working for the benefit of the patient.

\section{References}

1. Hussain HY (2017) Future medical research challanges. Res Med Eng Sci 1(1): 1.

2. Beik J, Khademi S, Attaran N, Sarkar S, Ghadiri H, et al. (2017) A nanotechnology based strategy to increase the efficiency of cancer diagnosis and therapy: Folate conjugated gold nanoparticles. Curr Med Chem 24(39): 4399-4416.

3. Fluet GG, Merians AS, Qiu Q, Saleh S, Ruano V, et al. (2014) Robotic/ virtual reality intervention program individualized to meet the specific sensorimotor impairments of an individual patient: a case study. Int J Disabil Hum Dev 13(3): 401-407. 
Creative Commons Attribution 4.0 International License

For possible submissions Click Here

Submit Article

\begin{tabular}{|l} 
RMES $\begin{array}{c}\text { Researchin } \\
\text { Medica I } \\
\text { Engineering } \\
\text { Sciences }\end{array}$ \\
Benefits of Publishing with us \\
B High-level peer review and editorial services
\end{tabular}

